\title{
RECIRCULATING CALCIUM HYDROXIDE SOLUTION: A PRACTICAL CHOICE FOR ON-FARM HIGH SOLIDS LIGNOCELLULOSE PRETREATMENT
}

\author{
W. Sympson, S. E. Nokes, A. N. Hickman \\ The authors are William Sympson ${ }^{\mathrm{a}}$, Engineering Associate, Sue E. Nokes ${ }^{\mathrm{a} *}$, Department Chair, Amanda N. Hickman ${ }^{\mathrm{a}}$, \\ Engineering Associate, ${ }^{a}$ Department of Biosystems and Agricultural Engineering, University of Kentucky, Lexington, \\ Kentucky, USA. Corresponding author: Sue E. Nokes, 128 C.E. Barnhart Bld. Lexington, KY, 40546; phone: 859-218- \\ 4328; sue.nokes@uky.edu.
}

\begin{abstract}
Pretreatment is considered a necessary step in the use of lignocellulosic biomass for biochemical conversion to higher value products. There are multiple choices of chemicals for pretreatment in industrial settings, however on-farm choices are constrained to those that function well at near ambient conditions with minimal specialized equipment, personnel training, and require limited waste disposal. This work presents a novel pretreatment system biomass using a recirculating, saturated calcium hydroxide (lime) solution in an up-flow, high solids (14-16\% w/w) configuration at ambient conditions. In this system, lime solids were efficiently consumed, post-pretreatment washing of substrate was not required, and energy and resources were conserved. Pretreatment effectiveness was assessed by glucose yield comparisons for both switchgrass and corn stover. Based on mean glucose yields from $5 \mathrm{~mm}$ corn stover, lime pretreatment would require $350 \mathrm{~kg}$ of dry stover to produce 100 $\mathrm{kg}$ glucose at a chemical cost of $\$ 8.67$ while $\mathrm{NaOH}$ pretreatment would require $300 \mathrm{~kg}$ of chemical at a cost of $\$ 22.38$.
\end{abstract}

Keywords. Calcium Hydroxide, lime, lignocellulose, pretreatment, high solids, bulk hydrolysis. 


\section{INTRODUCTION}

Biomass transport is one of the most costly processes in biofuel production; biochemical conversion on farm would allow for the harvesting, storage, and conversion to be completed in the same location (Klein-Marcuschamer and Blanch, 2015). However a successful on-farm conversion process requires optimization of all stages of operation: storage, size reduction, and pretreatment must be integrated.

The vast majority of studies related to the chemical pretreatment of lignocellulose have been conducted at the laboratory scale with conditions such as elevated temperatures and pressures, finely ground particles sizes, and with chemicals and processes that produce wastes which require careful disposal (Kumar et al., 2009). While these types of processes can produce an effective pretreatment, they are impractical or too expensive for a simple on-farm process. A practical on-farm process would be conducted under ambient conditions, using a relatively safe, inexpensive chemical which can be recovered, minimizing waste by-products, while achieving a reasonable level of pretreatment.

The use of calcium hydroxide (lime) as a lignocellulosic pretreatment chemical is not a new idea; it has been evaluated in many studies (Ayeni et al., 2013), resulting in recommended pretreatment temperatures of $100-120{ }^{\circ} \mathrm{C}$ with treatment periods defined in hours (Chang et al., 1997), or for temperatures of $50-60{ }^{\circ} \mathrm{C}$ with the treatment periods defined in days or weeks (Xu et al., 2010). More recent work has re-examined the performance of lime at ambient temperatures (Rodrigues et al., 2016) and even below ambient temperatures (Khor et al., 2015), however in general these studies concluded that high temperatures were necessary to achieve sufficient glucose yield (Carey, 2014). In addition, these studies autoclaved the biomass prior to pretreatment; a practice which is impractical on-farm.

Previous studies did not adjust the process for $\mathrm{Ca}(\mathrm{OH})_{2}$ 's limited solubility in water. $\mathrm{Ca}(\mathrm{OH})_{2}$ exhibits an interesting property that the solubility actually decreases with increasing temperature. For example, at $20{ }^{\circ} \mathrm{C}, 1.65 \mathrm{~g} / \mathrm{L}$ of $\mathrm{Ca}(\mathrm{OH})_{2}$ will dissolve into solution, whereas only $0.071 \mathrm{~g} / \mathrm{L}$ will 
dissolve into solution at $100{ }^{\circ} \mathrm{C}$ (Association, 2007); contrast this with the high temperature recommendation for $\mathrm{Ca}(\mathrm{OH})_{2}$ pretreatment and a logical disconnect is apparent. Lime's low solubility produces a far less aggressive alkali solution by limiting the hydroxyl ion concentration available in solution, which likely accounts for the longer recommended pretreatment period (Yan et al., 2015). The reviewed literature commonly recomended a static lime loading rate of $0.10 \mathrm{~g} / \mathrm{g}$ dry matter $(10 \%$ w/w) (Yan et al., 2015).

Undissolved $\mathrm{Ca}(\mathrm{OH})_{2}$ solids are problematic because they will deposit on the substrate instead of performing the desired pretreatment. The unreacted $\mathrm{Ca}(\mathrm{OH})_{2}$ on the biomass also necessitates significant neutralization prior to hydrolysis, typically requiring large volumes of wash water or chemical neutralization with acids (Rodrigues et al., 2016). Pretreatment processes using alkali solutions result in final $\mathrm{pH}$ values typically above 10 ; whereas $\mathrm{pH}$ levels acceptable for enzymatic hydrolysis are typically 4.8-5.5. Neutralization methods used in $\mathrm{Ca}(\mathrm{OH})_{2}$ pretreatment studies include washing the solids with de-ionized water (Yan et al.; 2015), adding organic or mineral acids to the solids (Falls and Holtzapple, 2011), or using gaseous carbon dioxide to reduce pH and enable the recovery of calcium as calcium carbonate (Park et al., 2010).

The biomass solids content of the pretreatment step impacts all aspects of the conversion process including water use, materials handling, and ultimately process economics (Modenbach and Nokes, 2012). The majority of pretreatment studies have been conducted with initial dry matter solids loadings ranging between $5 \%$ and $10 \%(\mathrm{w} / \mathrm{w})$. A process is considered high solids at or greater than $15 \%(w / w) ;$ this demarcation signifies the transition from a slurry to stackable solids (Modenbach and Nokes, 2012). The use of high solids may offer economic advantages through improved efficiencies, however the lack of free water may slow chemical reactions, increased viscosity complicates material handling and mixing, and there is a potential to produce inhibitory compounds at higher concentrations (Rodrigues et al., 2016). 


\subsection{Objectives}

The overall goal of this research was to determine whether $\mathrm{Ca}(\mathrm{OH})_{2}$ is an effective pretreatment when the solubility limitations of $\mathrm{Ca}(\mathrm{OH})_{2}$ are accounted for in the pretreatment design. The second objective of this work was to test the hypothesis that no neutralization of the substrate would be needed if $\mathrm{Ca}(\mathrm{OH})_{2}$ solids did not deposit on the biomass, because only solubilized $\mathrm{Ca}(\mathrm{OH})_{2}$ was circulated through the biomass.

\section{Materials AND Methods}

\subsection{Feedstock}

The substrates used for this work were Zea mays (corn stover) and Panicum virgatum (switchgrass). The corn stover was Becks 6175 hybrid, harvested in the fall of 2013at the C. Oran Little Research Center in Woodford County, KY. The Alamo switchgrass was harvested in February 2014 at the North Farm in Fayette County, KY. Both substrates were baled and stored in barns and moved to the lab for use as needed. The materials were air dried in the lab to a moisture content of approximately $8.5 \%$ wet basis (w.b.).. For the nominal $5 \mathrm{~mm}$ particle size experiments, the feedstock was ground to pass a 5mm screen in a C.S. Bell No. 10 hammer mill, and stored in standard plastic feed sacks until use. The stored moisture content varied seasonally but held within a range of $7 \%$ to 9\% w.b. Moisture content was measured with an Ohaus MB35 Halogen moisture analyzer. The substrates were not autoclaved before pretreatment.

Untreated (raw) corn stover and switchgrass were prepared and analyzed according to NREL Laboratory Analytical Procedures (LAP) (Sluiter et al., 2012). Samples were analyzed in duplicate by HPLC using Bio-Rad Aminex HP-87P column at $78{ }^{\circ} \mathrm{C}$ with $0.45 \mathrm{~mL}$ min-1 flow rate and a water mobile phase. 


\subsection{Treatment Vessel}

The treatment vessel was designed as an up-flow reactor (Figure 1a). The up-flow configuration was used to prevent neutralization from atmospheric carbon dioxide. The vessels consisted of $473 \mathrm{~mL}$ canning jars, (obtained from McMaster-Carr) using standard tin bands and lids. Stainless steel wire mesh screens were used in the vessel above and below the feedstock to prevent solids from leaving the vessel. The vessels were loaded with a total mass equivalent to 38.5 grams of bone dry substrate, then capped with a screen before installing the lid and band. Six treatment vessels were placed on an elevated platform for each experimental run as shown in Figure 1b.

\subsection{Pumping System}

In order to operate six vessels simultaneously, two pump drives, each with three pump heads (Masterflex), were used to provide flow. The pumps drew the saturated solution from a four liter glass reservoir, and forced flow through each vessel and back to the reservoir (Figure 2). The pump drives were operated at $50 \mathrm{rpm}$, delivering $140 \mathrm{~mL} / \mathrm{min}$ to each vessel, resulting in a vessel volume turnover rate of 42 times per hour, which ensured a high hydroxyl ion availability.

A drive with a single pump head was used to maintain a saturated calcium hydroxide solution by recirculating the reservoir contents at $280 \mathrm{~mL} / \mathrm{min}$ through a filter housing, (McMaster-Carr) with a 5-micron synthetic water filter. The filter was sized to trap the lime solids on the upstream side of the filter, thus preventing dispersal into the reservoir and throughout the substrate.

\subsection{Pretreatment}

The calcium hydroxide used for all experiments was purchased from Acros Organics and loaded at $10 \%(\mathrm{w} / \mathrm{w})$ of the total dry matter. The lime was added to approximately one liter of water, agitated and then pumped into the filter. The reservoir recirculation process then ensured the reservoir contained a saturated lime solution. Once the defined pretreatment period elapsed, the recirculation 
pump drives were reversed and the lime solution was pumped out of the treatment vessels to the reservoir and reused for the next pretreatment run. The pretreatment process was operated for 7 days at ambient laboratory temperature of $22^{\circ} \mathrm{C}$ (Rodrigues et al., 2016).

Control experiments were performed with a) no pretreatment (raw substrate), b) recirculating water, and c) $\mathrm{Ca}(\mathrm{OH})_{2}$ without recirculation. The raw substrate control received no modification. The recirculating water control experiments were conducted with a separate de-ionized (DI) water reservoir. For the static controls, i.e., no recirculation, identical pretreatment vessels were used without holes for fittings. The static pretreatment contained 20 grams dry matter, $10 \mathrm{~mL}$ DI water per gram dry matter (10\% solids loading), $5 \%$ or $10 \%(\mathrm{w} / \mathrm{w})$ lime, and the contents thoroughly mixed. Static pretreatment experiments were conducted for 7 days at $22{ }^{\circ} \mathrm{C}$.

Sodium hydroxide $(\mathrm{NaOH})$ was used as the comparative benchmark to assess lime pretreatment performance. $\mathrm{NaOH}$ pretreated was conducted in the same vessel configuration as the other static controls, at $10 \%$ (w/w) chemical loading, $20 \mathrm{~g} \mathrm{DM}$ and $200 \mathrm{~mL}$ DI water for a 10\% dry matter solids loading (Modenbach and Nokes, 2014). Both switchgrass and corn stover ( $\mathrm{n}=3$ vessels each) were pretreated for 7 days at ambient laboratory temperature of $22{ }^{\circ} \mathrm{C}$.

All $\mathrm{NaOH}$ pretreated materials were washed following pretreatment to a neutral $\mathrm{pH}$. Raw substrate and solids pretreated in the static control experiments were also washed. The solids were placed on a coffee filter in a Buchner funnel with applied vacuum and rinsed with DI water; the $\mathrm{pH}$ was monitored by placing standard laboratory $\mathrm{pH}$ paper on the solids. Washed solids went directly to enzymatic hydrolysis. Unwashed solids (and the raw control) were moved directly to enzymatic hydrolysis with no post-pretreatment conditioning.

\subsection{Enzymatic Hydrolysis}

Substrate (washed or unwashed) was enzymatically hydrolyzed without drying prior to hydrolysis. Enzymatic hydrolysis was done according to NREL Protocol NREL/TP-510-42629 with 
each sample divided and treated in triplicate. Moisture content was determined using an Ohaus MB35 Halogen moisture analyzer. The cellulase enzyme used for experiments was commercial liquid cellulase enzyme - Novozyme CTec2, lot no. VCS00002. The enzyme preparation was loaded at the manufacturer recommended dosage of $30 \% \mathrm{w} / \mathrm{w}$ of cellulose. CTec 2 has been reported to contain 120 FPU/mL (Vivekanand et al., 2014). This translates to a loading rate of 30 FPU per gram cellulose.

In all experiments, enzyme blanks and filter paper controls (Whatman \#1 filter paper) were prepared and included in triplicate for each enzymatic hydrolysis event. A $0.1 \mathrm{M}$ sodium citrate buffer was used for $\mathrm{pH}$ control during hydrolysis. The impact of hydrolysis $\mathrm{pH}$ was tested at $\mathrm{pH} 4.8$ and $\mathrm{pH}$ 5.5. The hydrolysis process was performed in a shaking table incubator for 72 hours at $50{ }^{\circ} \mathrm{C}$ and 150 RPM. After 72 hours, the enzymatic hydrolysis process was stopped by placing the samples in a 93 ${ }^{\circ} \mathrm{C}$ water bath for 15 minutes to denature the enzyme protein. The samples were cooled on the bench, vortexed for 5-10 seconds and $1.5 \mathrm{~mL}$ decanted into labeled micro-centrifuge tubes. The samples were then centrifuged at 5,000 RPM for 10 minutes. Glucose was quantified in the post centrifugation samples using the YSI 2900D (Yellow Springs, OH) biochemistry analyzer.

Average values of cellulose content were used in this work for corn stover and switchgrass (SunGrant 2007). The value of $37.5 \%(w / w)$ cellulose content was used as the basis for all calculations for both feedstocks. The use of an average value for cellulose content did not negatively impact the results since all the comparisons examined relative performance instead of absolute values.

\subsection{Saccharification Analysis}

The YSI 2900D biochemistry analyzer was calibrated before each analysis event resulting in a sample analysis range of $0.05-25 \mathrm{~g} / \mathrm{L}$ glucose. The samples to be analyzed were placed in a 24 well tray in a pre-determined random order. Four $9.0 \mathrm{~g} / \mathrm{L}$ standards and two DI water standards were included as a quality control measure with each group of samples analyzed. The data were analyzed in SAS version 9.4. 


\section{RESULTS AND DISCUSSION}

\subsection{Relative Lime Effectiveness}

The $\mathrm{pH}$ at the end of the pretreatment period for static (non-recirculating) treatments with $10 \%$ (w/w) $\mathrm{Ca}(\mathrm{OH})_{2}$ loading rates was consistently above $\mathrm{pH} 11$. The static samples with a 5\% (w/w) $\mathrm{Ca}(\mathrm{OH})_{2}$ loading rate had a final value between $\mathrm{pH} 6$ and $\mathrm{pH} 7$, indicating that the hydroxyl ions had been fully reacted.

Figure 3 presents the glucose yields from the various lime pretreatments and controls. The hydrolysis of biomass pretreated with $\mathrm{Ca}(\mathrm{OH})_{2}$ at a $10 \%(\mathrm{w} / \mathrm{w})$ loading rate significantly outperformed water, no pretreatment, and $\mathrm{Ca}(\mathrm{OH})_{2}$ at a $5 \%(\mathrm{w} / \mathrm{w})$ loading rate but showed no significant difference between recirculating and static treatments. As a result of these experiments, no additional work was done with water only pretreatment, $\mathrm{Ca}(\mathrm{OH})_{2}$ loading rates below $10 \%(\mathrm{w} / \mathrm{w})$, or static $\mathrm{Ca}(\mathrm{OH})_{2}$ pretreatments since the performance of a recirculating system was confirmed to be equivalent to the static pretreatment in terms of glucose yield upon enzymatic hydrolysis, and our objective was to determine if the recirculating system eliminating the need for extensive washing post pretreatment.

\subsection{Water Conservation}

Glucose yields from pretreated $5 \mathrm{~mm}$ substrate (switchgrass and corn stover) for washed/unwashed comparisons were pooled and analyzed (table 1). The mean value for all the washed treatments was $0.271 \mathrm{~g} \mathrm{G} / \mathrm{g}$ DM compared to $0.264 \mathrm{~g} \mathrm{G} / \mathrm{g}$ DM for the unwashed samples, and these means were not significantly different. Given that there was no statistically significant difference between the treatments, washing was deemed unnecessary for the recirculated $\mathrm{Ca}(\mathrm{OH})_{2}$ pretreated substrate.

At laboratory scale, the environmental impact of washing at 100 - $300 \mathrm{~mL}$ per gram of dry matter (Wang and Cheng, 2011) is negligible. However, scaling that wash water volume to a theoretical 100-ton ( $\sim 91$ tonnes) bunker, 36’W x 50’ $\mathrm{L}$ x 12’ $\mathrm{H}(\sim 11 \mathrm{~m} \mathrm{~W}$ x 15m L x 4m H), with one- 
pass washing results in a requirement of 2.4-7.2 $\times 10^{6}$ gallons $\left(\sim 9-27 \times 10^{3} \mathrm{~m}^{3}\right)$ of water, resulting in a significant environmental and economic impact. This recirculating lime pretreatment process conserves on the order of $10,000 \mathrm{~m}^{3}$ of water per tonne of biomass; which renders this process attractive for on-farm use.

\subsection{Comparison of $\mathrm{NaOH}$ and Lime Pretreatment}

Table 1 compares the glucose yields resulting from enzymatic saccharification of the $\mathrm{Ca}(\mathrm{OH})_{2}$ and $\mathrm{NaOH}$ pretreated materials. The glucose yields of recirculating $\mathrm{Ca}(\mathrm{OH})_{2}$ pretreated switchgrass and corn stover met or exceeded those found in literature studies (table 2), performed under similar conditions. In general, the $\mathrm{Ca}(\mathrm{OH})_{2}$ treatments detailed in the literature are less practical for on-farm use (higher temperatures, more griding, etc.) and achieved glucose yields slightly lower than those achieved with the recirculating system at ambient conditions used in this study. From a systems point of view, the lower glucose yields from the lime pretreatments may be offset by the lower water requirement for washing and the reduced waste disposal problems from limetreated biomass compared to the $\mathrm{NaOH}$-treated biomass.

\section{4. $\mathrm{Ca}(\mathrm{OH})_{2}$ Solution Reuse}

Once the pretreatment process has been completed, the solution is pumped off and stored in the reservoir, to be used again on the next batch after circulating back through the $\mathrm{Ca}(\mathrm{OH})_{2}$-laden filter. The reservoir filtration prevents the dispersion of insoluble lime solids throughout the substrate, and allows any unreacted lime to be present for the next batch - this approach conserves lime, minimizes or possibly eliminates wash water, while simultaneously ensuring a fully saturated solution. The use of the filtration and the reuse of the lime solution during the extent of these experiments did not negatively impact glucose yields evidenced by consistent glucose yields from batch to batch, as well as by comparison with the results of others' work. The lime solution was 
sampled on two separate occasions, the samples centrifuged and analyzed on the YSI without

modification. In both cases, glucose was undetectable. The presence of divalent calcium ions has been suggested as protective of carbohydrates by a crosslinking effect under alkaline conditions (Yan et al., 2015).

\subsection{Chemical Costs}

The costs for lime compared to $\mathrm{NaOH}$ become an important consideration at the farm scale. To that end, a bulk price quote for both calcium and sodium hydroxides was obtained from a national chemical company for 25 tons delivered to Lexington, KY (Brenntag, 2015). The lime was quoted at $\$ 225 /$ ton, while $\mathrm{NaOH}$ (caustic flakes/pellets) was quoted at $\$ 680 /$ ton. Using the mean glucose yields from this work, the bare chemical cost per 100kg of glucose produced is $\$ 8.67$ for lime and $\$ 22.38$ for $\mathrm{NaOH}$. $\mathrm{NaOH}$ costs approximately 2.6 times the cost of lime, yet only increases the hydrolysis efficiency by $17 \%$. Stated differently, because of this difference in efficiency about $300 \mathrm{~kg}$ of $\mathrm{NaOH}$ pretreated corn stover dry matter would be required to produce $100 \mathrm{~kg}$ of glucose, whereas about 350 $\mathrm{kg}$ of dry matter would be needed for lime pretreated stover. Taking into account the potential cost of feedstock, $\mathrm{Ca}(\mathrm{OH})_{2}$ pretreatment would cost on the order of half the cost of $\mathrm{NaOH}$ for the same amount of glucose produced.

\section{Conclusion}

A key aspect of the recirculating $\mathrm{Ca}(\mathrm{OH})_{2}$ pretreatment system presented here is the absence of undissolved lime particles on the biomass being pretreated. Therefore, solids pretreated with recirculating lime can transition directly to enzymatic hydrolysis without a washing step. Sodium citrate hydrolysis buffer was sufficient to adjust and maintain the system $\mathrm{pH}$ for enzymatic hydrolysis. The environmental and economic values of conserving water by not requiring washing the solids prior to enzymatic hydrolysis is a major benefit of this pretreatment system. Additionally, spent lime solution can be recycled by recovering the calcium via carbonation or land applied as a soil 
amendment. In contrast, sodium wastewater cannot be land applied without energy intensive sodium recovery due to salinization risks.

Chemical costs show a lower cost per kilogram of glucose for lime pretreatment on-farm than for $\mathrm{NaOH}$ pretreatment. When all the factors, such as cost, safety, ease of use, infrastructure requirements et al. are considered, lime represents a practical chemical choice for an on-farm pretreatment.

\section{ACKNOWLEDGEMENTS}

The authors sincerely acknowledge the financial support of the United States Department of Agriculture National Institute for Food and Agriculture, Biomass Research and Development Initiative grant \#2011-10006-30363. This is publication No. 16-05-030 of the Kentucky Agricultural Experiment Station and is published with the approval of the Director. This work was supported by the National Institute of Food and Agriculture, U.S. Department of Agriculture, Hatch- Multistate project under accession number 1003563.

\section{REFERENCES}

Association, N. L. (2007). Lime Terminology, Standards \& Properties. Fact Sheet: Properties of Lime. N. L. Association. Arlington, VA.

Ayeni, A. O., Hymore, F. K., Mudliar, S. N., Deshmukh, S. C., Satpute, D. B., Omoleye, J. A., \& Pandey, R. A. (2013). "Hydrogen peroxide and lime based oxidative pretreatment of wood waste to enhance enzymatic hydrolysis for a biorefinery: Process parameters optimization using response surface methodology." Fuel 106: 187-194.

Brenntag (2015). Lime \& NaOH Bulk Pricing. W. Sympson. Lexington, KY.

Carey, B. D. (2014). Field Implementation of Phanerochaete Chrysosporium Biomass Pretreatment: Fungal Identification and Inoculation Techniques. Biosystems and Agricultural Engineering. Lexington, KY, University of Kentucky. Master's Thesis.

Chang, V. S., Burr, B., \& Holtzapple, M. T. (1997). "Lime pretreatment of switchgrass." Applied Biochemistry and Biotechnology 63-5: 3-19. 
Falls, M. and M. T. Holtzapple (2011). "Oxidative Lime Pretreatment of Alamo Switchgrass." Applied Biochemistry and Biotechnology 165(2): 506-522.

Khor, W. C., Rabaey, K., \& Vervaeren, H. (2015). "Low temperature calcium hydroxide treatment enhances anaerobic methane production from (extruded) biomass." Bioresource Technology 176: 181188.

Klein-Marcuschamer, D., \& Blanch, H. W. (2015). Renewable fuels from biomass: Technical hurdles and economic assessment of biological routes.AIChE Journal, 61(9), 2689-2701.

Kumar, P., D. M. Barrett, et al. (2009). "Methods for Pretreatment of Lignocellulosic Biomass for Efficient Hydrolysis and Biofuel Production." Industrial \& Engineering Chemistry Research 48(8): 3713-3729.

Modenbach, A. A. and S. E. Nokes (2012). "The use of high-solids loadings in biomass pretreatment-a review." Biotechnology and Bioengineering 109(6): 1430-1442.

Modenbach, A. A. and S. E. Nokes (2014). "Effects of Sodium Hydroxide Pretreatment on Structural Components of Biomass." Transactions of the Asabe 57(4): 1187-1198.

Park, J.Y., Shiroma, R., Al-Haq, M.I., Zhang, Y., Ike, M., Arai-Sanoh, Y., Ida, A., Kondo, M. and Tokuyasu, K., (2010). "A novel lime pretreatment for subsequent bioethanol production from rice straw - Calcium capturing by carbonation (CaCCO) process." Bioresource Technology 101(17): 6805 6811.

Rodrigues, C. I. S., Jackson, J. J., \& Montross, M. D. (2016). “A molar basis comparison of calcium hydroxide, sodium hydroxide, and potassium hydroxide on the pretreatment of switchgrass and miscanthus under high solids conditions.” Industrial Crops and Products 92: 165-173.

Sluiter, A., Hames, B., Ruiz, R., Scarlata, C., Sluiter, J., Templeton, D., and Crocker, D. 2012. Determination of structural carbohydrates and lignin in biomass. Laboratory Analytical Procedure. Golden, CO. National Renewable Energy Laboratory.

SunGrant (2007). Composition of Herbaceous Biomass Feedstocks. N. C. Center. Brookings, SD, South Dakota State University.

Vivekanand, V., Olsen, E. F., Eijsink, V. G., \& Horn, S. J. (2014). "Methane Potential and Enzymatic Saccharification of Steam-exploded Bagasse." Bioresources 9(1): 1311-1324.

Wang, Z. Y. and J. J. Cheng (2011). "Lime Pretreatment of Coastal Bermudagrass for Bioethanol Production." Energy \& Fuels 25(4): 1830-1836.

Xu, J., Cheng, J. J., Sharma-Shivappa, R. R., \& Burns, J. C. (2010). "Lime pretreatment of switchgrass at mild temperatures for ethanol production." Bioresource Technology 101(8): 29002903.

Yan, Z., Li, J., Chang, S., Cui, T., Jiang, Y., Yu, M., Zhang, L., Zhao, G., Qi, P., \& Li, S. (2015)"Lignin relocation contributed to the alkaline pretreatment efficiency of sweet sorghum bagasse." Fuel 158: 152-158. 


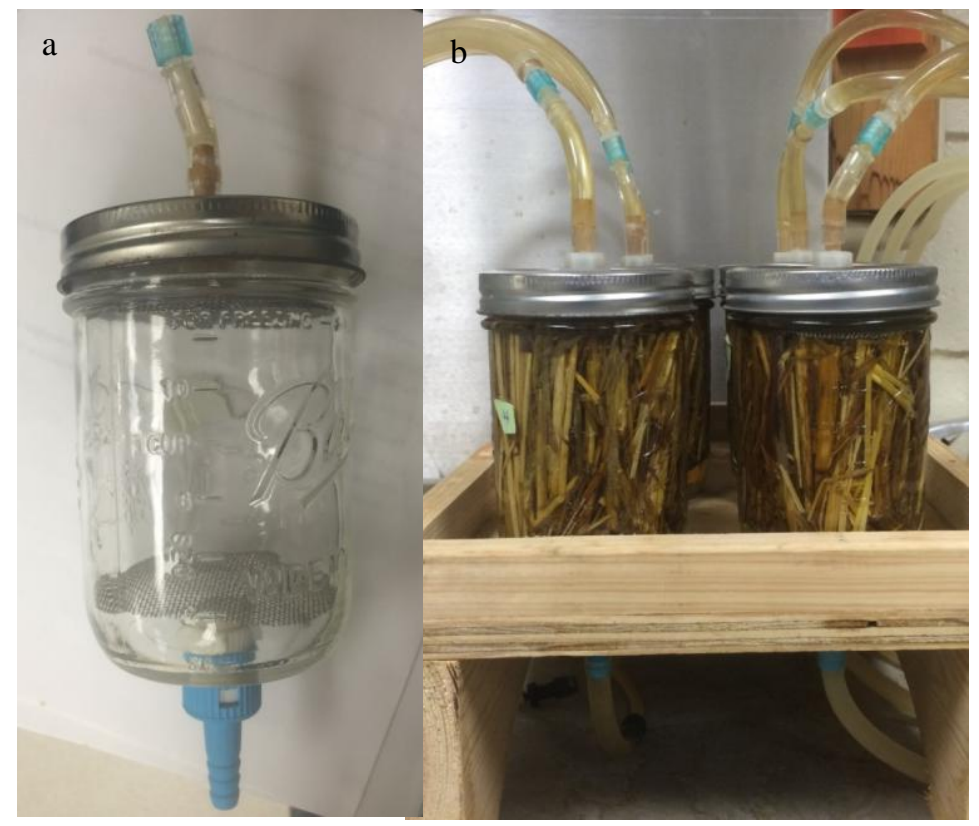

Figure 1: a) Vessel used for up-flow treatment showing in-flow port on the bottom of the vessel and exit port on the top. b) Stand showing six vessels in use simultaneously during high solids recirculating $\mathrm{Ca}(\mathrm{OH})_{2}$ pretreatment. 


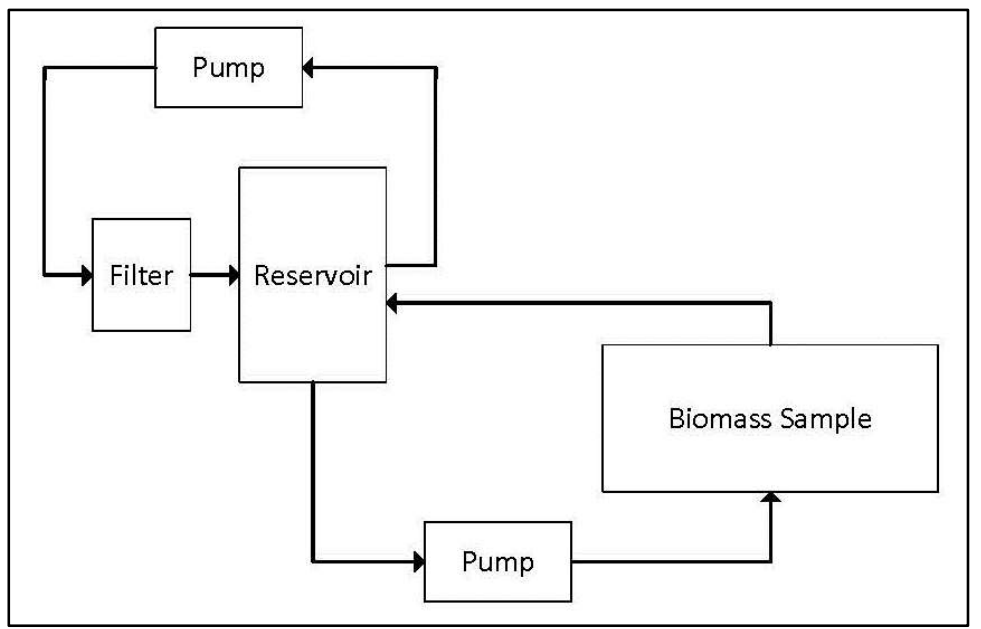

Figure 2: Experimental pretreatment system schematic showing recirculating system for the saturated lime solution. The filter retained $\mathrm{Ca}(\mathrm{OH})_{2}$ solids, followed by the reservoir where the saturated $\mathrm{Ca}(\mathrm{OH})_{2}$ solution was stored. 


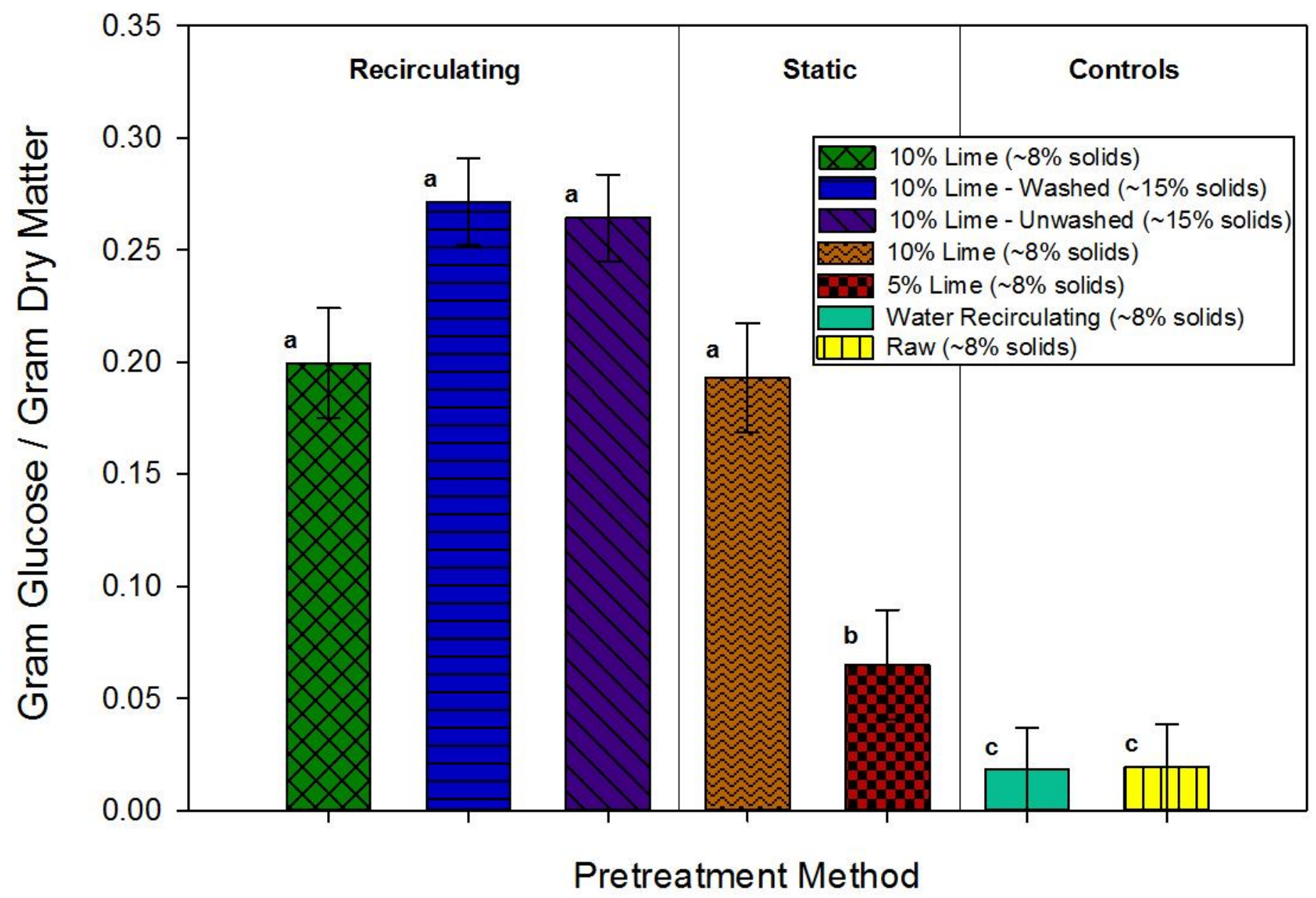

Figure 3: Comparison of lime loading rate, configuration (static or recirculating), solids loading, and controls on $5 \mathrm{~mm}$ switchgrass pretreated for 7 days at $22^{\circ} \mathrm{C}$ and $\mathrm{pH} 4.8$. Error bars are RMSE.

${ }^{\mathrm{a}, \mathrm{b}, \mathrm{c}}$ Means with different letters are statisitically different at the $\alpha=0.05$ level. 
Table 1. Mean glucose yields \pm RMSE (root mean square error) from the enzymatic saccharification of each $5 \mathrm{~mm}$ substrate and $\mathrm{pH}$ treatment $\left(7\right.$ day, $22^{\circ} \mathrm{C}, 10 \%$ lime recirculating, high solids $\sim 15 \%(w / w)$ ) combination. Glucose yields are expressed in grams of glucose per gram of dry biomass. Yield Ratio of Lime to $\mathrm{NaOH}$ represents the simple ratio of the yields, expressed as a percent.

\begin{tabular}{|c|c|c|c|}
\hline Treatment & $\begin{array}{l}\text { Lime Glucose Yield } \\
\text { (g G/g DM) }\end{array}$ & $\begin{array}{l}\text { NaOH Glucose Yield } \\
\text { (g G/g DM) }\end{array}$ & $\begin{array}{r}\text { Yield Ratio of } \\
\text { Lime/NaOH }\end{array}$ \\
\hline Corn stover (pH 4.8) & $0.286^{\mathrm{a}} \pm 0.034$ & $0.335^{b} \pm 0.034$ & $85 \%$ \\
\hline Corn stover (pH 5.5) & $0.271^{\mathrm{a}} \pm 0.044$ & $0.334^{b} \pm 0.044$ & $81 \%$ \\
\hline Switchgrass (pH 4.8) & $0.245^{\mathrm{c}} \pm 0.023$ & $0.293^{\mathrm{d}} \pm 0.023$ & $84 \%$ \\
\hline Switchgrass (pH 5.5) & $0.243^{c} \pm 0.033$ & $0.293^{\mathrm{d}} \pm 0.033$ & $83 \%$ \\
\hline
\end{tabular}


Table 2: Summary of literature results from comparable pretreatment systems.

Calcium Hydroxide Pretreatment

\begin{tabular}{|c|c|c|c|c|c|c|c|c|c|}
\hline Substrate & $\begin{array}{l}\text { Particle } \\
\text { Size }\end{array}$ & $\begin{array}{c}\text { Pretreatment } \\
\text { Time }\end{array}$ & $\begin{array}{c}\text { Pretreatment } \\
\text { Temperature } \\
\left({ }^{\circ} \mathrm{C}\right)\end{array}$ & $\begin{array}{c}\% \\
\mathrm{Ca}(\mathrm{OH})_{2}\end{array}$ & $\begin{array}{c}\text { Total } \\
\text { Solids (\%) }\end{array}$ & $\begin{array}{c}\text { Cellulose } \\
\text { Content } \\
(\%)\end{array}$ & $\begin{array}{l}\text { Neutralization } \\
\text { Method }\end{array}$ & $\begin{array}{l}\text { Yield (g G/g } \\
\text { DM) }\end{array}$ & Reference \\
\hline Switchgrass & $<0.4 \mathrm{~mm}$ & 2 hours & 121 & 10 & 10 & 38 & Acetic acid & 0.250 & $\begin{array}{c}\text { Chang et al., } \\
1997\end{array}$ \\
\hline Switchgrass & $<2 \mathrm{~mm}$ & 96 hours & 21 & 10 & 10 & 38 & Water & 0.231 & $\mathrm{Xu}, 2009$ \\
\hline Corn Stover & $6 \mathrm{~mm}$ & 2,688 hours & 25 & 50 & 10 & 37.7 & $\begin{array}{l}\text { Hydrochloric } \\
\text { acid }\end{array}$ & 0.251 & $\begin{array}{c}\text { Kim \& } \\
\text { Holtzapple, } 2005\end{array}$ \\
\hline Corn Stover & $6 \mathrm{~mm}$ & 672 hours & 55 & 50 & 10 & 37.7 & $\begin{array}{l}\text { Hydrochloric } \\
\text { acid }\end{array}$ & 0.341 & $\begin{array}{c}\text { Kim \& } \\
\text { Holtzapple, } 2005\end{array}$ \\
\hline Corn Stover & $2 \mathrm{~mm}$ & 168 hours & 20 & 10 & 40 & 37.7 & Water & 0.037 & $\begin{array}{l}\text { Rodrigues et al, } \\
2016\end{array}$ \\
\hline \multicolumn{10}{|c|}{$\mathrm{NaOH}$ Pretreatment } \\
\hline Substrate & $\begin{array}{l}\text { Particle } \\
\text { Size }\end{array}$ & $\begin{array}{c}\text { Pretreatment } \\
\text { time }\end{array}$ & $\begin{array}{c}\text { Temperature } \\
\left({ }^{\circ} \mathrm{C}\right)\end{array}$ & $\% \mathrm{NaOH}$ & $\begin{array}{c}\text { Total solids } \\
\qquad(\%)\end{array}$ & $\begin{array}{c}\text { Cellulose } \\
\text { content } \\
(\%)\end{array}$ & $\begin{array}{c}\text { Neutralization } \\
\text { Method }\end{array}$ & $\begin{array}{l}\text { Yield (g G/g } \\
\text { DM) }\end{array}$ & Reference \\
\hline Switchgrass & $<0.4 \mathrm{~mm}$ & 2 hours & 121 & 10 & 10 & 38 & Acetic Acid & 0.263 & $\begin{array}{c}\text { Chang et al., } \\
1997\end{array}$ \\
\hline Corn Stover & $2 \mathrm{~mm}$ & 168 hours & 20 & 10 & 40 & 37.7 & Water & 0.183 & $\begin{array}{c}\text { Rodrigues et al., } \\
2016\end{array}$ \\
\hline
\end{tabular}

